Esta obra está sob o direito

de Licença Creative

Commons Atribuição 4.0

Internacional.

\title{
PORTADORES DE AUTISMO E EDUCAÇÃO INCLUSIVA
}

\section{RESUMO}

José Silva de Menezes ${ }^{37}$

Dílson Cavalcante Tenório ${ }^{38}$

Betijane Soares de Barros ${ }^{39}$

Durante o processo de formação acadêmica, percebe-se que os discentes dos cursos de formação de professor, não são contemplados minunciosamente sobre a educação inclusiva, em especial, voltada para o autismo. Observa-se ainda que quando estes profissionais chegam ao mercado de trabalho, se deparam com desafios que não foram contemplados na formação inicial. Assim, este artigo tem como objetivo promover uma reflexão acerca das concepções históricas que têm influenciado o processo de inclusão dos alunos com autismo. A inclusão da criança com autismo em escolas de ensino regular tem sido bastante discutida no âmbito educacional devido à complexidade das características e dificuldades apresentadas por elas quando inseridas na escola. Quando tratamos sobre o processo de inclusão escolar de crianças com autismo, diretamente recaímos sobre o papel do professor, visto que ele é o principal responsável e mediador da aprendizagem dos alunos. Neste artigo, fez-se um caminho sobre historico do autismo, perpassando pela a problemática da inclusão escolar, as leis que amparam a inclusão e a inclusão do autista.

Palavras chave: inclusão, autismo, inclusão de autista.

\footnotetext{
37 Jaelson_menezes@hotmail.com

38 dilsontenorio4@hotmail.com

39 bj-sb@hotmail.com
} 


\section{INTRODUÇÃO}

$\mathrm{Na}$ era da inclusão, a sociedade, assim como os profissionais da área da educação necessitam estar preparados para incluir crianças, adolescentes e demais pessoas com dificuldades e/ou transtornos, como por exemplo as crianças com autismo. Estes devem ser tratados como seres humanos que possuem o direito de viver numa sociedade livre. $O$ autismo, na atualidade, é um tema bastante abordado por diversos autores e pesquisas. Demonstrando necessidade em discuti-lo (PAULA, PEIXOTO, 2019).

A importância da temática discorre ainda pelo fato de como deve ser tratada a inclusão nas instituições escolares, pois, a mesma vai além de somente matricular a pessoa com necessidades educativas especiais, é preciso realmente inseri-la no processo de aprendizagem. Mesmo com todas as dificuldades é neste ambiente que o aluno necessita ser estimulado e preparado para viver em sociedade (COUTINHO,2013).

A inclusão do autismo em sala de aula ainda é um desafio para todos, mesmo sendo um direito da criança garantido por lei, que também assegura apoio aos professores. No entanto, muitas escolas alegam não estarem preparadas para a inclusão, o que demanda trazer o assunto para a discussão e propagar informações sobre o TEA - Transtorno do Espectro Autista (CUNHA,2015).

A inclusão do autismo em sala de aula requer adaptações e estratégias diferenciadas, mas é muito positiva para todos, professores, alunos em geral e família. Nós só temos a aprender com a diversidade e não devemos nos paralisar frente aos desafios que a inclusão apresenta. Fatores como diagnóstico precoce do autismo, contato próximo com a família, apoio dos profissionais especializados que atendem a criança, sensibilização dos funcionários da escola e a constante troca entre os professores favorecem a realização da inclusão (CAVACO, 2014).

É importante destacar que a criança com autismo pode ter acesso à educação formal, pois ele tem o direito de matrícula, bem como de receber apoio especializado na sala de Atendimento Educacional Especializado (AEE), visando propagar a inclusão do mesmo e desenvolvê-lo em uma vida estudantil muito benéfica, inclusive. Neste contexto, o profissional deve possuir competências e habilidades para desenvolvê-lo (CUNHA, 2015).

(CAVACO, 2014) diz que ao compreender o autismo, abrir-se-á portas para o entendimento do nosso próprio desenvolvimento. Menciona ainda que há dificuldade em entendê-los devido à uma incapacidade do ser humano de se ajustar à diferença, seja ela que tipo for.

\section{METODOLOGIA E MÉTODO}

Trata se de uma revisão bibliográfica sistemática integrativa que permite a síntese de um artigo original a partir de execução de métodos sistemáticos respondendo a uma questão específica e analisando criticamente os artigos selecionados. Realizou-se um levantamento de estudos nacionais que abordavam a inclusão escolar de crianças com TEA. As pesquisas nacionais foram feitas em portais de dados disponíveis na web: Literatura Latino-Americana e do Caribe em Ciências da Saúde (LILACS), Biblioteca Virtual em Saúde (BVS), Scientific Electronic Library Online (SciELO) e Portal de Periódicos da CAPES. 
Inicialmente, realizou-se uma leitura dos títulos e resumos dos artigos encontrados na busca. Posteriormente, os artigos selecionados foram obtidos na íntegra e examinados de acordo com os critérios de inclusão estabelecidos. Para a análise dos estudos, foram considerados os seguintes aspectos: autores, ano e revista de publicação do estudo, objetivos dos artigos.

\section{UM BREVE HISTÓRICO SOBRE AUTISMO}

Segundo o Ministério da Saúde, a história dos precursores do TEA teve seu destaque entre o século XVII e século XIX. Pois, até esse período o diagnóstico era nomeado de "idiotia" e cobria todo o campo da psicopatologia de crianças e adolescentes. Deste modo, a idiotia pode ser considerada precursora na compreensão de diversos transtornos mentais, como por exemplo as psicoses infantis, a esquizofrenia infantil e o autismo (BERCHERIE, 1998 apud BRASIL, 2015).

O Transtorno do Espectro Autista, já foi conhecido na literatura como transtorno Autístico, autismo da infância, autismo infantil e autismo infantil precoce (KLIN, 2006 apud PAULA, PEIXOTO, 2019).

(PAULA, PEIXOTO, 2019) comenta que demonstrando preocupação em evoluir com o tema, bem como com o uso de conceitos e definições acerca do TEA. Apesar da concepção do termo ser efetivada no ano de 1911, os primeiros estudos sobre autismo, somente foram realizados no ano de 1943 pelo psiquiatra Leo Kanner. O mesmo apresentou, por meio de pesquisa, indícios de que várias crianças apresentavam características individualizadas, quando comparadas às outras síndromes.
O Autismo Infantil foi definido por Kanner, em 1943, sendo inicialmente denominado Distúrbio Autístico do Contato Afetivo, como uma condição com características comportamentais bastante específicas, tais como: perturbações das relações afetivas com o meio, solidão autística extrema, inabilidade no uso da linguagem para comunicação, presença de boas potencialidades cognitivas, aspecto físico aparentemente, normal, comportamentos ritualísticos, início precoce e incidência predominante no sexo masculino.

(COUTINHO,2013) diz que Em 1944, Asperger propôs em seu estudo a definição de um distúrbio que ele denominou Psicopatia Autística, manifestada por transtorno severo na interação social, uso pedante da fala, desajeitamento motor e incidência apenas no sexo masculino. $\mathrm{O}$ autor utilizou a descrição de alguns casos clínicos, caracterizando a história familiar, aspectos físicos e comportamentais, desempenho nos testes de inteligência, além de enfatizar a preocupação com a abordagem educacional destes indivíduos.

Estes trabalhos tiveram grande impacto na literatura, porém em momentos distintos. Foram rapidamente absorvidas pela comunidade científica.

A abordagem etiológica do Autismo Infantil, proposta por Kamer, salientava a existência de uma distorção do modelo familiar, que ocasionaria alterações no desenvolvimento psicoafetivo da criança, decorrente do caráter altamente intelectual dos pais destas crianças. Apesar desta proposição, o autor não deixou de assinalar que algum fator biológico, existente na criança, poderia estar envolvido, uma vez que as alterações comportamentais eram 
verificadas precocemente, o que dificultaria a aceitação puramente relacional.

Em 1980, o autismo foi reconhecido pela primeira vez e inserido em uma nova classe de transtornos, os transtornos invasivos do desenvolvimento (KLIN, 2006). Na atualidade, é utilizado o termo transtorno do espectro autista e este está incluído no Manual Diagnóstico e Estatístico de Transtornos Mentais (DSM$\mathrm{V})$, na categoria Transtornos do Neurodesenvolvimento (TND) (APA, 2014).

Ressalta-se que no ano de 2014, no lançamento do DSM-V, houve uma fusão do transtorno autista, do transtorno de Asperger e do transtorno global do desenvolvimento no Transtorno do Espectro Autista. Essa fusão foi realizada pois a American Psychiatric Association (2014), por meio de levantamentos e estudos identificou que: [o]s sintomas desses transtornos representam um continuo único de prejuízos com intensidades que vão de leve a grave nos domínios de comunicação social e de comportamentos restritivos e repetitivos em vez de constituir transtornos distintos. Essa mudança foi implementada para melhorar a sensibilidade e a especificidade dos critérios para o diagnóstico de transtorno do espectro autista e para identificar alvos mais focados de tratamento para os prejuízos específicos observados.

É um transtorno de desenvolvimento que causa problemas na linguagem, dificuldades de comunicação, interação social e comportamento das pessoas.

Em 2013, no lançamento da quinta edição do Manual Diagnóstico e Estatístico de Transtornos Mentais (DSM-V), o autismo recebeu uma nova nomenclatura: Transtorno do Espectro do Autismo (TEA).
A ciência e especialistas podem avaliar e estudar melhor os graus de autismo a partir dessa consideração de espectros. $\mathrm{Ou}$ seja, isso quer dizer que é uma condição que muda de pessoa para pessoa.

Assim, dependendo do espectro, o autismo pode ser mais leve ou mais disfuncional. Isso é variável.

(CUNHA,2015), menciona que o TEA possui "a abrangência de distintos níveis do transtorno, classificando-os de leve, moderado e severo". Esses níveis irão possibilitar ao profissional a identificação do grau de comprometimento e com isso, as crianças e demais indivíduos com autismo, que passam por avaliações formais, são diagnosticados com diferentes níveis, tornando peculiar e individual o funcionamento de cada pessoa acometida com o transtorno.

\section{EDUCAÇÃO INCLUSIVA E LEIS QUE A AMPARAM.}

(SILVA, PEDRO, JESUS,2018) diz que falar em inclusão nos remete às discussões sobre o direito à igualdade e o direito à diferença. As sociedades são, por mais homogêneas que tentem aparentar, multiculturais em sua essência. Não há país ou grupo social no qual todos os indivíduos sejam ou hajam da mesma forma, ou que professem a mesma fé, ou tenham as mesmas aspirações. Tanto nas suas ações cotidianas em busca da sobrevivência, como nas interpretações simbólicas da existência, os seres humanos são absolutamente únicos.

As autoras acima ainda comentam que incluir, portanto, não significa homogeneizar, mas, ao contrário, dar espaço para a expressão das diferenças. Uma diferença que se mostra não como desigualdade, mas como afirmação 
contundente do princípio de que todos são iguais no universo dos direitos humanos, da liberdade de expressão, da sobrevivência com dignidade e das oportunidades.

Ao longo de muitos anos lutamos para ter nossos direitos garantidos e conseguimos te-los através de leis. Para os portadores de necessidades especiais não seria diferente para que tivessem seus direitos garantidos, serem respeitados, vistos como cidadãos. Para isso, também teve que ocorrer manifestações da sociedade, o povo teve que expressar sua indignação perante o governo para que esse começasse a ver os deficientes como parte da sociedade.

Algumas declarações foram criadas: a Declaração Universal dos Direitos do Homem (1948); Declaração Mundial de Educação para Todos (1990); e a Declaração de Salamanca (1994).

Para os portadores de necessidades especiais a Declaração de Salamanca foi especial. Essa declaração é o resultado da Conferência Mundial sobre Necessidades Educativas Especiais, que ocorreu na Espanha e teve como foco a questão da educação para crianças com necessidades especiais. A declaração diz:

Todas as crianças têm direito fundamental à educação e deve ser dada a oportunidade de obter e manter um nível adequado de conhecimento. Cada criança tem características, interesses, capacidades e necessidades de aprendizagem que lhes são próprias. Os sistemas educativos devem ser projetados e os programas aplicados de modo que tenham em vista toda a gama dessas diferentes características e necessidades. As pessoas com necessidades educativas especiais devem ter acesso à escola regular que deverão integrá-las numa pedagogia centrada na criança, capaz de atender a essas necessidades. As escolas regulares, com essa orientação integradora, representam os meios mais eficazes de combater as atitudes discriminatórias, criando comunidades acolhedoras, construindo uma sociedade integradora e alcançando educação para todos, além de proporcionar uma educação efetiva à maioria das crianças e melhorar tanto a eficiência como a relação custo-benefício de todo o sistema educativo. (UNESCO, 1994)

Atualmente a nossa legislação descreve no Capítulo V, os direitos dos educandos especiais, nos art. 58,59 e 60, artigos estes que encontramos na Lei de Diretrizes e Bases da Educação Nacional, que incluiu em 20 de dezembro de 1996, a educação especial no contexto efetivo da educação em âmbito nacional.

Art. 58. Entende-se por educação especial, para os efeitos desta Lei, a modalidade de educação escolar, oferecida preferencialmente na rede regular de ensino, para educandos portadores de necessidades especiais.

$\S 1^{\circ}$ Haverá, quando necessário, serviços de apoio especializado, na escola regular, para atender às peculiaridades da clientela de educação especial.

$\S 2^{\circ} \mathrm{O}$ atendimento educacional será feito em classes, escolas ou serviços especializados, sempre que, em função das condições específicas dos alunos, não for possível a sua integração nas classes comuns de ensino regular.

$\S 3^{\circ}$ A oferta de educação especial, dever constitucional do Estado, tem início na faixa etária de zero a seis anos, durante a educação infantil. (LDBEN, 1996).

Importante destacar, a educação inclusiva, embora trate prioritariamente de crianças, não se refere somente a elas, mas de todos, jovens e adultos. Pela histórica prática de exclusão, em nosso país temos 
um grande contingente de jovens e adultos analfabetos ou analfabetos funcionais que demandam oportunidade de reinserção na escola.

O trabalho da escola de inserir o aluno especial em uma classe comum de ensino e não o separar em uma sala a parte é essencial para a vida social do portador de necessidade especial, para que ocorra a interação do mesmo com o ambiente escolar, (RIBAS apud JACOMELI, 2020) comenta que é melhor para qualquer criança conviver em classes heterogêneasfrequentadas por portadores ou não de deficiência, para que ela possa integrar-se com a riqueza das diferenças que todos nós possuímos.

Direito à educação: efetividade dos princípios reguladores do ensino. "Art. $6^{\circ}$ São direitos sociais a educação, a saúde, a alimentação, o trabalho, a moradia, o transporte, o lazer, a segurança, a previdência social, a proteção à maternidade e à infância, a assistência aos desamparados, na forma desta Constituição.

As leis que norteiam a educação inclusiva são:

\section{- $\quad 1989$ - Lei no 7.853/89.}

Dispõe sobre o apoio às pessoas portadoras de deficiência e sua integração social. Define como crime recusar, suspender, adiar, cancelar ou extinguir a matrícula de um estudante por causa de sua deficiência, em qualquer curso ou nível de ensino, seja ele público ou privado.

- 1990 - Estatuto da Criança e do Adolescente - Lei ${ }^{\circ}$.

O ECA repete o mandamento constitucional que obriga o Estado assegurar à criança atendimento educacional especializado aos portadores de deficiência, preferencialmente na rede regular de ensino. Não desistam dessa luta e busquem o Judiciário. ... Trata-se de dever do Estado, que deve ser priorizado pelo Agente Público.

- 1990 - Declaração Mundial de Educação para Todos.

O objetivo último da Declaração Mundial sobre Educação para Todos é satisfazer as necessidades básicas da aprendizagem de todas as crianças, jovens e adultos. ... Essas metas representam um "piso" - não um "teto" - para o desenvolvimento contínuo dos serviços e dos programas de educação.

- 1994 - Declaração de Salamanca.

Uma das implicações educacionais orientadas a partir da Declaração de Salamanca refere-se à inclusão na educação. Segundo o documento, “o princípio fundamental da escola inclusiva é o de que todas as crianças deveriam aprender juntas, independentemente de quaisquer dificuldades ou diferenças que possam ter.

- 1996 - Lei de Diretrizes e Bases da Educação Nacional - Lei no 9.394/96

Estabelece que a educação básica deve ser inclusiva, para atender a uma política de integração dos estudantes com necessidades educacionais especiais nas classes comuns dos sistemas de ensino. Isso exige que a formação dos docentes das diferentes etapas inclua conhecimentos relativos à educação desses alunos.

- 1999 - Decreto $\mathrm{n}^{\circ} 3.298$ que regulamenta a Lei ${ }^{\circ} 7.853 / 89$.

Regulamenta a Lei no 7.853, de 24 de outubro de 1989, dispõe sobre a Política 
Nacional para a Integração da Pessoa Portadora de Deficiência, consolida as normas de proteção, e dá outras providências.

O docente precisa fomentar a discussão sobre o direito do aluno com necessidades educativas especiais a usufruir de uma boa escola, com um currículo comum e flexível às suas peculiaridades, para efetivamente desenvolver-se uma educação inclusiva.

Os professores capacitados, para serem assim denominados, devem ter uma disciplina em sua formação inicial a respeito da educação especial e da educação inclusiva, além de adquirir competências para perceber as necessidades educacionais específicas dos estudantes e flexibilizar a ação pedagógica para atender as suas

Precisa buscar respostas educativas que favoreçam o sucesso escolar de seus alunos. É fundamental que sua ação pedagógica contemple os pilares propostos no Informe Delors (2000): aprender a aprender, aprender a fazer, aprender a viver junto e aprender a ser.

Para colocar a educação inclusiva em prática em suas salas de aula e na escola como um todo é necessário:

- $\quad$ ser flexível e adaptável.

- Construa uma "base".

- $\quad$ Não policiar o gênero.

- $\quad$ Certificar-se de que suas atividades fora de sala de aula sejam acessíveis.

\section{A inclusão de alunos com autismo.}

(OLIVEIRA, 2020) comenta que quando se fala sobre a inclusão da criança com autismo na escola de ensino regular, deve-se pensar também no professor, pois este, muitas vezes, não está preparado para receber os alunos com autismo. Diante disso, este artigo apresenta como problemática: qual é o papel do professor frente à inclusão escolar de crianças com autismo na rede regular de ensino? O professor é visto como mediador no processo inclusivo; é ele quem promove o contato inicial da criança com a sala de aula, pois é o responsável por incluí-lo nas atividades com toda a turma.

A escola recebe uma criança com dificuldades em se relacionar, seguir regras sociais e se adaptar ao novo ambiente. Esse comportamento é logo confundido com falta de educação e limite. E por falta de conhecimento, alguns profissionais da educação não sabem reconhecer e identificar as características de um autista, principalmente os de alto funcionamento, com grau baixo de comprometimento. Os profissionais da educação não são preparados para lidar com crianças autistas e a escassez de bibliografias apropriadas dificulta o acesso à informação na área. (Santos, 2008).

(SANTOS apud OLIVEIRA, 2020) afirma que a escola tem papel importante na investigação diagnóstica, uma vez que é o primeiro lugar de interação social da criança separada de seus familiares. É onde a criança vai ter maior dificuldade em se adaptar às regras sociais - o que é muito difícil para um autista.

A flexibilização do currículo é uma forma de estabelecer o vínculo e a cumplicidade entre pais e educadores, para que, no espaço escolar, ocorra a coesão de vontades, entre educadores e família, das competências estabelecidas para a educação do aluno com autismo. Essa revolução estrutural acontece através do manejo do currículo frente aos desafios enfrentados com a vinda da criança com autismo à escola regular. 
Para VALLE e MAIA (2010), a adaptação curricular se define como "o conjunto de modificações que se realizam nos objetivos, conteúdos, critérios e procedimentos de avaliação, atividades e metodologia para atender as diferenças individuais dos alunos".

O professor deve observar seu aluno e incentivá-lo com entusiasmo, aproximando-se devagar e sempre com um objetivo traçado. A interação com a família é importante. Laço de companheirismo e solidariedade facilita $o$ trabalho do educador. Muitas ideias vão surgindo quando se conhece e motiva o aluno. $\mathrm{O}$ processo pode parecer lento, porém, tornase eficaz a partir de uma aula planejada e direcionada por metas e objetivos preestabelecidos.

Para (OLIVEIRA, 2020) o docente deve ter consciência clara do importante papel que desempenha ao iniciar o processo de inclusão de uma criança com necessidades educacionais especiais associadas ao autismo infantil. Um professor hábil pode abrir a porta para várias oportunidades: como cada criança com autismo processa a informação e quais são as melhores estratégias de ensino devido à singularidade de seus pontos fortes, interesses e habilidades em potencial.

A (Declaração de Salamanca, 1994), diz que é preciso repensar a formação de professores especializados, a fim de que estes sejam capazes de trabalhar em diferentes situações e possam assumir um papel-chave nos programas de necessidades educativas especiais. Deve ser adaptada uma formação inicial não categorizada, abarcando todos os tipos de deficiência, antes de se enveredar por uma formação especializada numa ou em mais áreas relativas a deficiências específicas.
Para (OLIVEIRA,2020) o professor deve desenvolver metodologias de aprendizagem para que o aluno autista consiga se comunicar e se desenvolver. $\mathrm{O}$ conteúdo do programa de uma criança autista deve estar de acordo com seu desenvolvimento e potencial, de acordo com a sua idade e de acordo com o seu interesse; o ensino é o principal objetivo a ser alcançado, e sua continuidade é muito importante, para que elas se tornem independentes. Trabalhar com alunos autistas exige o desenvolvimento de práticas e estratégias pedagógicas que acolham todos e respeitem as diferenças.

A incapacidade de desenvolver um relacionamento interpessoal se mostra na falta de resposta ao contato humano e no interesse pelas pessoas, associada a uma falha no desenvolvimento do comportamento normal, de ligação ou contato. Na infância, estas deficiências se manifestam por uma inadequação no modo de se aproximar, falta de contato visual e de resposta facial, indiferença ou aversão a afeto e contato físico (Gauderer, 2011).

Em muitas vezes este comportamento, pode não ser compreendido pela comunidade escolar.

\section{CONCLUSÃO}

Diante do que foi visto e escrito, conclui-se que a inclusão dos alunos autista, é o melhor caminho para o desenvolvimento pleno de suas habilidades.

Apesar de que a inclusão ainda é um desafio a ser concretizado por diversos fatores, principalmente, pela estrutura organizacional da educação que muitas das vezes não atinge o aluno típico, muito menos o atípico.

Acrescenta-se a isso a formação inicial do docente que muitas das vezes não 
dá subsídios para lidar com um aluno dentro do espectro. Por isso, por ser um transtorno complexo, é necessário um esforço individual de busca constante pelo conhecimento e compreensão de que cada autista é único. Assim, as metodologias utilizadas serão diversas, a fim de atender as áreas que precisam ser desenvolvidas.

Assim, é imprescindível que o professor e os profissionais que têm contato com o aluno autista, busquem diariamente, estratégias para que o ensino chegue a ele de forma igualitária e acompanhem de perto as demandas que emergem. Vale abordar que é um trabalho árduo e que não tem resultados imediatos, ou seja, é um constante processo.

Mesmo com todo aparato das leis, a educação inclusiva ainda se esbarra nesses dois entraves. Profissionais que não são preparados adequadamente para um trabalho de inclusão. A própria escola não está preparada para aceitar as diferenças e até mesmo a sociedade não está.

\section{REFERÊNCIAS}

BRASIL. Diretrizes Nacionais para a Educação Especial na Educação Básica. Ministério da Educação. Secretaria de Educação Especial. Brasília: MEC/SEESP, 2001.

BRASIL. Declaração de Salamanca e linha de ação sobre necessidades educativas especiais. Brasília: UNESCO, 1994.

BRASIL, Ministério da Saúde. Linha de Cuidado para a Atenção Integral às Pessoas com Transtorno do Espectro do Autismo e suas Famílias na Rede de Atenção Psicossocial do Sistema Único de Saúde. Brasília, DF: Ministério da Saúde, 2015.

\section{CAVACO, N. Minha criança é} diferente? Um Manual de Ajuda para Pais e Professores. 1. ed. Rio de Janeiro: Wak Editora, 2014. COUTINHO, A. A. et al. DO DSM-I AO DSM-5: Efeitos do diagnóstico psiquiátrico "Espectro Autista" sobre pais e crianças. 2013. Disponível em:https://psicanaliseautismoesaudepublic a.wordpress.com/2013/04/11/do-dsm-i-aodsm-5-efeitos-do-diagnostico-psiquiatricoespectro-autista-sobre-pais-e-criancas.

Acesso em: 04/03/2021.

\section{CUNHA, E. Autismo e Inclusão:}

psicopedagogia e práticas educativas na escola e na família. 6 ed. Rio de Janeiro:

Wak Ed., 2015.

CUNHA, Gracielle Rodrigues da; BORDINI, Daniela; CAETANO, Sheila Cavalcante. Autismo, transtornos do espectro do autismo. In: CAETANO, Sheila Cavalcante; LIMA-HERNANDES, Maria Célia; PAULA, Fraulein Vidigal de; RESENDE, Briseida Dôgo de; MÓDOLO, Marcelo (Orgs.). Autismo, linguagem e cognição. Jundiaí: Paco, 2015.

DECLARAÇÃO DE SALAMANCA.

Disponível

em: http://portal.mec.gov.br/seesp/arquivos /pdf/salamanca.pdf. Acesso em: 18 março. 2021.

GAUDERER, E. C.; PRAÇA, E. T. P. $O$. Uma reflexão acerca da inclusão de aluno autista no ensino regular. 2011. OLIVEIRA, F. L. Autismo e inclusão escolar: os desafios da inclusão do aluno autista. In. Revista Educação. Disponível em:https://educacaopublica.cecierj.edu.br/ acesso em 11/04/2021. 
PAULA, Jessyca Brennand de, PEIXOTO, Mônica Ferreira. A inclusão do aluno com autismo na educaçãoinfantil: desafios e possibilidades. Cadernos da Pedagogia, v. 13, n. 26, p. 31-45, out/Dez 2019.

JACOMELI, Renam Bezerra. A inclusão de alunos com necessidades educacionais especiais no ensino regular. 2020.

SANTO, A.M.E.; COELHO, M. M.

Necessidades Educativas Especiais de Caráter Permanente/Prolongado: no contexto da escola inclusiva. Castro Verde: Cenfocal, 2006.

SANTOS, R. K.; VIEIRA, A. M. E. C. S. Transtorno do Espectro do Autismo (TEA): Do Reconhecimento à Inclusão no Âmbito Educacional. Revista

Includere, Rio Grande do Norte, v. 3, n. 1, p. 219-232. 2017. Disponível em:

https://periodicos.ufersa.edu.br/index.php/i ncludere/article/view/7413. Acesso em: 15 março. 2021.

VALLE, T. G. M.; MAIA, A. C.

B. Aprendizagem e comportamento humano. São Paulo: Cultura Acadêmica, 2010 .

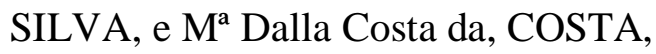
Vanize Dalla Costa, JESUS, Eliane Maria de. Educação inclusiva. 2018. 